\title{
Pós-colheita de uva 'Itália' revestida com filmes à base de alginato de sódio e armazenada sob refrigeração
}

\author{
Postharvest of grape envolved with films of sodium alginate and cold storage
}

Ana Carolina Almeida MIGUEL ${ }^{1 \star}$, João Ricardo Pecini Stein DIAS ${ }^{1}$, Silvana ALBERTINI ${ }^{1}$, Marta Helena Fillet SPOTO ${ }^{1}$

\begin{abstract}
Resumo
Este trabalho teve como objetivo avaliar o efeito da aplicação de película à base de alginato de sódio em diferentes concentrações na conservação pós-colheita de uva 'Itália' armazenada sob refrigeração. Cachos de uva 'Itália' colhidos em Pirapora (SP) foram selecionados, previamente higienizados com solução de álcool etílico a $30 \%$, imersos em solução de cloreto de cálcio a $0,6 \%$ por 2 minutos e, em seguida, em emulsão de alginato de sódio a 0,$25 ; 0,50 ; 0,75$ e $1,00 \%$, antes de serem mantidos sob refrigeração $\left(4 \pm 0,7{ }^{\circ} \mathrm{C} ; 49,5 \%\right.$ UR) por 29 dias. Avaliou-se a cada sete dias a porcentagem de perda de peso dos cachos, a coloração, a textura, os teores de Sólidos Solúveis (SS), de Acidez Titulável (AT) e de ácido ascórbico, o ratio (SS/AT), o pH e o teor de umidade das bagas. As bagas também foram avaliadas quanto à aceitação por 30 provadores não treinados. O tratamento com alginato a 1,00\% proporcionou melhor eficiência quanto à perda de massa, manutenção da textura, teores de umidade e de sólidos solúveis, além de propiciar menor intensidade no escurecimento das bagas. As bagas tratadas com película de alginato a $0,75 \%$ mostraram-se mais verdes, mais ácidas e com menor ratio. Ao longo de todo o período, todas as bagas tratadas com alginato foram bem aceitas pelos provadores. A cobertura com alginato a 1\% mostrou-se mais eficiente na conservação da uva 'Itália'. Palavras-chave: Vitis vinifera; qualidade; conservação; alginato de sódio.
\end{abstract}

\begin{abstract}
This work had as objective to evaluate the effect of the application of film made of sodium alginate in different concentrations in the postharvest conservation of grape 'Italia' under refrigeration. Clusters of 'Itália' grape, harvested in Pirapora (São Paulo, Brazil) were selected, previously sanitized in alcohol solution 30\%, immersed in calcium chloride solution $0.6 \%$ for 2 minutes and after that, in film of sodium alginate at $0.25,0.50,0.75$ and $1.00 \%$, before kept under refrigeration $\left(4 \pm 0,7^{\circ} \mathrm{C} ; 49.5 \%\right.$ UR) for 29 days. It was evaluated at seven days, the percentage of loss of weight of the clusters, coloration, texture, contents of Soluble Solid (SS), Titratable Acidity (TA) and of ascorbic acid, the relation SS/TA (ratio), $\mathrm{pH}$ and the text of humidity of berries. The berries were also evaluated about the acceptance for 30 cloth provers not trained. The treatment with alginate $1 \%$ provided better efficiency about the loss of mass, maintenance of the texture, texts of humidity and soluble solids besides propitiating minor intensity in the browning of the berries. The berries treated with alginate $0.75 \%$ had revealed greener, more acid and lesser ratio. Throughout all the period, all the berries treated with alginate were well accepted for the provers. The covering with alginate $1 \%$ revealed the more efficient in the conservation of the 'Itália' grape.

Keywords: Vitis vinifer; quality; stored; sodium alginate.
\end{abstract}

\section{Introdução}

A perda de água, frequente durante as operações comerciais, constitui um dos mais importantes problemas na pós-colheita da uva de mesa (SALUNKHE; DESAI, 1984), tendo como primeira consequência visível, o escurecimento do engaço. Segundo Winkler et al. (1974), uma perda de água de 5\%, além da redução da massa e na consistência, resulta no murchamento de muitos frutos, afetando a aparência e a firmeza ideais para o consumo.

Esta perda depende, fundamentalmente, da cultivar, das práticas culturais adotadas e das condições climáticas onde as uvas são produzidas (SALUNKHE; DESAI, 1984), podendo este efeito ser minimizado com a adoção de técnicas apropriadas de manuseio pós colheita (CENCI, 1994).

Nos últimos anos tem havido crescente interesse pelo uso de coberturas comestíveis aplicáveis à superfície de produtos perecíveis
(CHITARRA; CHITARRA, 2005). A película de revestimento pode ser definida como uma fina camada de material comestível depositada em um alimento, cuja finalidade é estender a vida pós-colheita de frutas e hortaliças. Tem ainda como objetivo inibir ou reduzir a migração de umidade, a difusão de oxigênio, dióxido de carbono e de aromas, pois atua como uma barreira semipermeável. Além disso, pode funcionar como veículo de antioxidantes, antimicrobianos e de flavorizantes, e promover melhoria na textura e na coloração do produto (KROCHTA; MULDER-JOHNSTON, 1997).

Alginatos são polímeros lineares compostos por resíduos de $\alpha$-L-gulurônico $(G)$ e $\beta$-D-manurônico $(M)$ presentes em proporções e sequência variáveis na parede celular e espaço intercelular de algas marrons. Para produzir o gel que é usado na formação dos filmes, o alginato deve reagir com cátions

Recebido para publicação em 10/8/2007

Aceito para publicação em 29/7/2008 (002748)

Departamento de Agroindústria, Alimentos e Nutrição, Escola Superior de Agricultura Luiz de Queiroz, Av. Pádua Dias, 11, CP 9, CEP 13418-900, Piracicaba - SP, Brasil,

E-mail: anaamiguel@yahoo.com.br

${ }^{*}$ A quem a correspondência deve ser enviada 
polivalentes, sendo os íons de cálcio os agentes gelificantes mais efetivos (ALLEN, 1963). O mecanismo de gelificação é um processo de troca iônica, no qual o sódio do alginato é trocado com o cálcio presente no meio gelificante através de uma ligação química entre dois grupos carboxila presentes em resíduos de ácido poligulurônico adjacentes. Os íons de cálcio têm por função manter as cadeias de alginato juntas pelas interações iônicas após a formação de pontes de hidrogênio entre as cadeias, produzindo gel com estrutura de rede tridimensional (KING, 1983).

As películas de alginato de sódio são formadas pela dispersão do pó em água sob agitação e com aquecimento $\left(70^{\circ} \mathrm{C}\right)$, sendo sua gelificação dependente da quantidade de cálcio presente ou adicionada ao alimento. $\mathrm{O}$ íon sódio $\left(\mathrm{Na}^{+}\right)$do alginato sofre permutação permitindo a formação de ligações iônicas cruzadas com o íon cálcio $\left(\mathrm{Ca}^{+2}\right)$ presente no meio gelificante. Esta permutação permite a formação de uma estrutura mais coesa promovendo uma fixação do filme na superfície do alimento. Estas coberturas são impermeáveis a óleos e gorduras (WHISTLER; BEMILLER; PASCHALL, 1984) e podem minimizar, em maior ou menor escala, as perdas de umidade dos alimentos em função da constituição da superfície do vegetal, haja vista que a umidade é perdida pela cobertura antes que o alimento se desidrate significativamente. São boas barreiras ao oxigênio (WHISTLER; BEMILLER, 1997), capazes de retardar a oxidação lipídica dos alimentos e melhorar o sabor, a textura e a adesão (KESTER; FENNEMA, 1986).

O presente trabalho teve como objetivo avaliar o efeito da aplicação de película à base de alginato de sódio na conservação pós-colheita de uva 'Itália' armazenada sob refrigeração.

\section{Material e métodos}

Cachos de uva 'Itália', procedentes da região de Pirapora (SP), safra 2006, foram transportados em caixas de papelão ao Departamento de Agroindústria, Alimentos e Nutrição da ESALQ/USP, onde foram selecionados, previamente higienizados com solução de álcool etílico a 30\%, por 1 minuto (KARABULUT, 2004), e imersos em solução de cloreto de cálcio a $0,6 \%$, por 2 minutos (FONTES, 2005). Em seguida, foram imersos em película de alginato de sódio, por 3 minutos, nas concentrações de 0,$25 ; 0,50 ; 0,75$ e $1 \%$ e mantidos sob refrigeração $\left(4 \pm 0,7^{\circ} \mathrm{C}\right.$; $49,5 \%$ UR) por 29 dias. A solubilização do alginato de sódio em água mineral foi conseguida pelo aquecimento da suspensão até $70^{\circ} \mathrm{C}$ e posterior resfriamento até $15^{\circ} \mathrm{C}$. As uvas assim tratadas foram deixadas por 10 minutos em ambiente refrigerado a $15^{\circ} \mathrm{C}$ para a secagem da película. Foram avaliados três cachos por tratamento, semanalmente, totalizando 75 unidades.

As variáveis analisadas foram: a) perda de massa: obtida por meio da pesagem de cada cacho e foi expressa em porcentagem, considerando-se as diferenças entre os pesos iniciais de cada cacho e os pesos após cada época de avaliação; b) coloração das bagas: determinada com colorímetro Minolta CR 400b, e expressa em Luminosidade $\left(\mathrm{L}^{*}\right)$, ângulo hue ou de cor $\left({ }^{\circ} \mathrm{h}\right)$ e cromaticidade (C) (MINOLTA CORP., 1004); c) sólidos solúveis (SS): determinados por leitura em refratômetro (AOAC, 1992); d) acidez titulável (AT): obtida por titulação do suco com solução de $\mathrm{NaOH}$ a $0,1 \mathrm{M}$, sendo os valores expressos em gramas de ácido tartárico por $100 \mathrm{~g}$ de suco (INSTITUTO ADOLFO LUTZ, 1985); e) ratio (relação SS/AT): obtido pelo quociente entre SS e AT; f)
pH: determinado por potenciômetro (AOAC, 1992); g) ácido ascórbico: obtido por titulação de alíquota de suco diluído em ácido oxálico a $0,5 \%$ com solução de 2,6 dicloro-fenol-indofenol de sódio, de acordo com Strohecker eHenning (1967); e h) textura: foi determinada com o auxílio de texturômetro Texture Test System, modelo TP-1 acoplado a um registrador automático de variação de força, operando com célula padrão de compressão de cisalhamento CS-1, com 10 lâminas de $1 / 8$ polegadas de espessura e ângulo de $90^{\circ}$. Cada amostra foi previamente pesada e colocada na célula de cisalhamento e compressão de tal forma que as lâminas das células tivessem ação paralela às amostras. Foi utilizado sensor ajustado para $300 \mathrm{lbf}$ (libras-força) e velocidade de descida do pistão de $20 \mathrm{~cm} \cdot \mathrm{min}^{-1}$. As medições foram feitas em doze bagas de cada tratamento e os resultados obtidos foram expressos em Newton (N); e i) umidade: determinada em balança determinadora de umidade Tecnal modelo B-TopRay, por radiação infravermelha, a qual permitiu expressar os resultados em porcentagem (\%).

Na mesma ocasião, os cachos foram avaliados sensorialmente quanto à aceitação por um grupo de 30 provadores não treinados, por dia de avaliação. Foi empregada a escala hedônica de nove pontos, sendo os extremos: valor 1 atribuído ao termo hedônico "desgostei extremamente" e valor 9 atribuído ao termo "gostei extremamente". Também foi solicitado que os provadores indicassem a intenção de compra em relação às amostras apresentadas (certamente compraria, provavelmente compraria, talvez compraria/não compraria, provavelmente não compraria, certamente não compraria) (MEILGAARD; CIVILLE; CARR, 1991).

O delineamento experimental utilizado foi inteiramente casualizado em esquema fatorial $5 \times 5$. Os fatores estudados foram as concentrações de alginato de sódio $(0,0,25,0,50,0,75$ e $1 \%)$ e o tempo de armazenamento (1; 8; 15; 22 e 29 dias). Foram utilizadas três repetições por tratamento, sendo cada uma composta por um cacho. Os resultados obtidos das análises físicas, químicas e sensoriais foram submetidos à análise de variância pelo teste $F$, a comparação das médias pelo teste de Tukey a $5 \%$ de probabilidade e os obtidos do acompanhamento da perda de massa foram submetidos à análise de regressão (GOMES, 1982).

\section{Resultados e discussão}

Analisando-se o efeito da concentração da película na perda de massa (Tabela 1), percebe-se que os cachos tratados com alginato a $1 \%$ foram os que apresentaram as menores perdas $(10,16 \%)$, seguidos das concentrações $0,75 \%(11,72 \%)$, $0,50 \%(11,79 \%), 0,25 \%(14,14 \%)$ e do testemunha $(16,43 \%)$. Os valores de perda de massa obtidos foram superiores aos citados por Kluge et al. (2002), que consideram que as uvas podem perder até $1,20 \%$ de água, sem que haja piora na aparência e comprometimento das características organolépticas. Pode-se afirmar que, apesar das uvas revestidas com alginato de sódio terem apresentado elevadas taxas de perda, estas não foram suficientes para causar murchamento das bagas, podendo esta perda ser atribuída à desidratação da própria película ao longo do armazenamento. De acordo com Kester e Fennema (1986), os filmes de polissacarídeos, a exemplo do alginato de sódio, podem retardar a perda de massa de alguns alimentos, quando aplicados na forma de gel, que age como agente sacrificante, ou 
seja, a umidade do gel evapora antes da desidratação do alimento revestido, indo ao encontro do observado neste trabalho.

Não houve interferência do fator tempo de armazenamento (dias) na luminosidade e no ângulo de cor das bagas, porém se verificou que os cachos tratados com alginato $1 \%$ apresentaram coloração mais amarelo-esverdeado escurecido $\left(L^{*}=37,19\right.$; $\left.{ }^{\circ} h=114,06 ; C=12,45\right)$ em relação aos demais tratamentos. Observou-se que os frutos do testemunha e o tratamento com película de alginato a $0,25 \%$ mostraram comportamento semelhante, indicado pela coloração levemente amarela $\left(\mathrm{L}^{*}=39,46,{ }^{\circ} \mathrm{h}=116,46\right.$ e C $=11,89 ; \mathrm{L}^{*}=38,68,{ }^{\circ} \mathrm{h}=115,07$ e C $=11,90$, respectivamente) e as concentrações de $0,50 \%$ e de $0,75 \%\left(L^{*}=38,36,{ }^{\circ} \mathrm{h}=118,37\right.$ e $\mathrm{C}=10,73 ; \mathrm{L}^{*}=38,07,{ }^{\circ} \mathrm{h}=118,89 \mathrm{e} \mathrm{C}=10,94$, respectivamente) apresentaram coloração verde pouco intensa, diferindo das demais (Tabela 2). O maior escurecimento (menor valor $L^{\star}$ ) para as bagas revestidas com a película deve ser atribuído à coloração do alginato que é levemente marrom.

Embora nos padrões norte-americanos de qualidade a cor da baga não seja considerada um requisito às variedades de uvas brancas (CARRARO; CUNHA, 1994) como a 'Itália', em geral os consumidores associam a coloração amarelada às frutas mais maduras e evitam adquirir frutas "verdes" (ácidas), preferindo as uvas de coloração verde-clara a verde-amarelada. Todos os tratamentos empregados se enquadraram na preferência de compra ao longo de todo o período de armazenamento, uma vez que apresentaram coloração verde-amarelada.

Em relação à cromaticidade observaram-se reduções nos valores com o avanço do período de armazenamento, indicando que houve diminuição da intensidade da cor das bagas (Tabela 2). Estes resultados são importantes uma vez que os produtos de coloração forte e brilhante são os preferidos, embora, em muitos casos, a coloração não se correlacione com seu valor nutritivo e com sua qualidade comestível (CHITARRA; ALVES, 2001).

$\mathrm{O}$ pH sofreu efeito significativo dos tratamentos com as películas e do período de armazenamento. A aplicação da película determinou aumento de $2,82 \%$ no pH (Tabela 3 ), e este incremento deve-se ao efeito das soluções filmogênicas, indo ao encontro do constatado por Fontes (2005) em maçãs minimamente processadas revestidas com alginato. De maneira geral, o $\mathrm{pH}$ manteve-se estável até o $22^{\circ}$ dia de armazenamento, seguido de aumento até o final do período. Estes resultados contrariam o observado por Cenci (1994), que verificou redução no pH de uva 'Niágara Rosada' armazenada sob refrigeração.

Pode-se verificar na Tabela 3 que as uvas que receberam película de alginato a $1 \%$ foram as que apresentaram os maiores

Tabela 1. Evolução da perda de massa fresca, representada por equações de regressão, em uvas 'Itália' revestidas com película à base de alginato de sódio e armazenadas sob refrigeração ( $4{ }^{\circ} \mathrm{C} ; 49,5 \%$ UR).

\begin{tabular}{lc}
\hline \multicolumn{1}{c}{ Tratamentos } & Equações de perda de massa fresca \\
\hline Testemunha & $\mathrm{Y}=0,2014+0,5622 . \mathrm{X} ; \mathrm{R}=0,9996^{* *}$ \\
Alginato de sódio a 0,25\% & $\mathrm{Y}=0,0668+0,4982 . \mathrm{X} ; \mathrm{R}=0,9960^{* *}$ \\
Alginato de sódio a 0,5\% & $\mathrm{Y}=0,8267+0,3943 . \mathrm{X} ; \mathrm{R}=0,9887^{* *}$ \\
Alginato de sódio a 0,75\% & $\mathrm{Y}=1,0702+0,3931 . \mathrm{X} ; \mathrm{R}=0,9813^{* *}$ \\
Alginato de sódio a 1\% & $\mathrm{Y}=-0,3369+0,3509 . \mathrm{X} ; \mathrm{R}=0,9968^{* *}$
\end{tabular}

$\mathrm{Y}$ : \% de perda de massa; $\mathrm{X}$ : dias de armazenamento; $\mathrm{e}^{* *}$ significativo a $1 \%$ de probabilidade. teores médios de Sólidos Solúveis (SS). Estes resultados discordam dos obtidos por Fontes (2005), que verificou que maçãs 'Royal Gala' minimamente processadas revestidas com película de alginato de sódio (1\%) apresentaram teor de sólidos solúveis semelhantes ao do testemunha. O período de armazenamento, por sua vez, não exerceu efeito sobre o teor de açúcares, o que pode ser atribuído ao padrão respiratório não climatérico. Detoni et al. (2005), em uvas 'Niágara Rosada' armazenadas a 1 e $14^{\circ} \mathrm{C}$ por 35 dias, também observaram manutenção nos teores de açúcares solúveis.

Com relação à acidez titulável, o testemunha apresentou acidez semelhante às uvas tratadas com a película nas concentrações de $0,25,0,50$ e $1,00 \%$, diferindo daquelas revestidas com alginato a $0,75 \%$ que se mostraram mais ácidas. Essa resposta foi provavelmente devida à desidratação das bagas, durante o armazenamento, e da redução da taxa respiratória, o que pode ter levado ao acúmulo de ácidos orgânicos, refletindo na maior acidez.

Analisando-se o efeito do período de armazenamento, observou-se que a acidez permaneceu estável (Tabela 3), o que vai ao encontro do constatado por Lavee e Nir (1986) e por Lima (1998), ou seja, que as alterações nos ácidos orgânicos de uvas são mínimas durante o armazenamento. De acordo com Carvalho e Chitarra (1984), valores de acidez superiores a 1,5\% podem ser considerados elevados; entretanto as médias, ao longo de todo o período de armazenamento, foram inferiores a 1,0 $\mathrm{g}$ de ácido tartárico. $100 \mathrm{~mL}^{-1}$ de suco, indicando a baixa acidez.

A relação SS/AT apresentou interação significativa entre os tratamentos e o período de armazenamento (Tabela 3). O menor valor dessa relação foi observado no tratamento com alginato a 0,75\%, como resultado da maior contribuição dos ácidos; ao passo que as uvas revestidas com alginato a $0,25 \%$ apresentaram os maiores valores. O sabor dos frutos é devido, em grande parte, ao balanço de ácidos e açúcares, o qual é avaliado pela relação SS/AT. Para uvas de mesa, são considerados adequados valores iguais ou superiores a 20:1 para esta relação (GAYET, 1993). Observou-se que todos os tratamentos apresentaram relação

Tabela 2. Coloração em uvas 'Itália' revestidas com películas de alginato de sódio em diferentes concentrações e armazenadas sob refrigeração ( $4 \pm{ }^{\circ} \mathrm{C} ; 49,5 \%$ UR).

\begin{tabular}{cccc}
\hline Variável & $\mathbf{L}^{*}$ & ${ }^{\mathrm{o}}$ & $\mathrm{C}$ \\
\hline $\begin{array}{c}\text { Concentração } \\
0 \%\end{array}$ & $39,46^{\mathrm{a}}$ & $116,46^{\mathrm{ab}}$ & $11,89^{\mathrm{ab}}$ \\
$0,25 \%$ & $38,68^{\mathrm{ab}}$ & $115,07^{\mathrm{b}}$ & $11,90^{\mathrm{ab}}$ \\
$0,50 \%$ & $38,36^{\mathrm{ab}}$ & $118,37^{\mathrm{a}}$ & $10,73^{\mathrm{b}}$ \\
$0,75 \%$ & $38,07^{\mathrm{ab}}$ & $118,89^{\mathrm{a}}$ & $10,94^{\mathrm{b}}$ \\
$1,00 \%$ & $37,19^{\mathrm{b}}$ & $114,06^{\mathrm{b}}$ & $12,45^{\mathrm{a}}$ \\
Dias & & & \\
1 & $37,96^{\mathrm{a}}$ & $116,37^{\mathrm{a}}$ & $12,24^{\mathrm{a}}$ \\
8 & $38,36^{\mathrm{a}}$ & $117,44^{\mathrm{a}}$ & $11,46^{\mathrm{ab}}$ \\
15 & $38,05^{\mathrm{a}}$ & $116,04^{\mathrm{a}}$ & $11,58^{\mathrm{ab}}$ \\
22 & $38,79^{\mathrm{a}}$ & $116,40^{\mathrm{a}}$ & $11,60^{\mathrm{ab}}$ \\
29 & $38,59^{\mathrm{a}}$ & $116,59^{\mathrm{a}}$ & $11,02^{\mathrm{b}}$ \\
$\mathbf{C V}(\%)$ & $\mathbf{5 , 4 9}$ & $\mathbf{3 , 2 9}$ & $\mathbf{1 4 , 2 5}$ \\
\hline
\end{tabular}

$L^{*}$ : luminosidade; $h^{o}$ : ângulo de hue ou de cor; $C$ : cromaticidade. Médias seguidas de pelo menos uma letra comum, nas colunas, não diferem significativamente entre si pelo teste de Tukey $(\mathrm{p}<0,05)$ 
SS/AT acima de 20, indicando frutos de qualidade e de sabor agradável. O equilíbrio entre os teores de açúcares e ácidos, ao longo do período de armazenamento, permite inferir que as uvas não apresentaram perda da qualidade organoléptica.

A aplicação de película à base de alginato de sódio, independente da concentração, determinou um incremento na textura das uvas (Tabela 3). Tal fato pode ser justificado pela imersão em solução de cloreto de cálcio anterior à aplicação da película, a qual pode ter contribuído para o enrijecimento do tecido superficial das frutas, haja vista que o cálcio atua formando ligações covalentes entre moléculas de pectina da parede celular e da lamela média, originando pectato de cálcio, o qual limita a ação de enzimas responsáveis pela perda de textura (SALUNKE; BOLIN; REDDY, 1991). Ao longo do período de armazenamento não foi verificada perda de textura, como se tem observado comumente para frutas e que tem sido atribuída à modificação nas estruturas e na composição da parede celular pela ação de enzimas (CHITARRA, 1999).

O período de armazenamento não mostrou efeito significativo na umidade das bagas, mas a aplicação de alginato em diferentes concentrações influenciou significativamente (Tabela 3). As uvas tratadas com alginato na concentração de $1 \%$ foram as que apresentaram maior teor de umidade, seguidas daquelas tratadas com $0,75,0,50$ e $0,25 \%$ e do testemunha (0\%), indo ao encontro dos resultados observados na perda de massa. Este efeito deve-se ao fato de que esta película pode ter reduzido significativamente a perda de umidade dos alimentos, uma vez que ela é consumida durante o armazenamento, evitando que a fruta se desidrate significativamente (WHISTLER; BEMILLER; PASCHALL, 1984). Este é um dado importante uma vez que os consumidores buscam frutas suculentas. A redução na porcentagem de umidade além de causar prejuízos à aparência pode levar à perda da qualidade gustativa, implicando na depreciação do produto.

Em relação ao teor de ácido ascórbico, verificou-se que os fatores concentração de película comestível e dias de armazenamento influenciaram significativamente (Tabela 3). Foi observado que o teor deste ácido foi diretamente proporcional ao aumento nas concentrações de alginato aplicadas ao produto, reafirmando que as coberturas de alginato são boas barreiras ao oxigênio, impedindo a difusão desse gás para o interior do produto, reduzindo a degradação deste ácido (WHISTLER; BEMILLER; PASCHALL, 1984). Ao longo do período de armazenamento, verificou-se tendência de aumento nos teores de ácido ascórbico, indicando que houve manutenção da qualidade das uvas. Estes resultados discordam dos encontrados por Detoni et al. (2005), que observaram decréscimo no teor de ácido ascórbico em uvas armazenadas a 1,14 e $24^{\circ} \mathrm{C}$.

Houve efeito significativo dos tratamentos e do período de armazenamento sobre a aceitação das uvas (Tabela 4). As uvas apresentaram diferenças significativas quanto à aceitação no $8^{\circ}$ e no $15^{\circ}$ dia de armazenamento para os tratamentos com 0,50 e $0,75 \%$ de alginato, que receberam as menores notas. Em relação ao efeito do tempo, verificou-se que os provadores não

Tabela 3. Valores médios das características físicas e químicas de uvas 'Itália’ revestidas com películas de alginato de sódio em diferentes concentrações e armazenadas sob refrigeração $\left(4^{\circ} \mathrm{C} ; 49,5 \%\right.$ UR).

\begin{tabular}{|c|c|c|c|c|c|c|c|}
\hline Variável & $\mathrm{pH}$ & Textura & $\mathrm{U}$ & AA & SS & $\mathrm{AT}$ & SS/AT \\
\hline \multicolumn{8}{|l|}{ Concentração } \\
\hline $0 \%$ & $3,44^{\mathrm{b}}$ & $3,84^{\mathrm{b}}$ & $10,06^{c}$ & $4,87^{\mathrm{c}}$ & $13,59^{\mathrm{b}}$ & $0,51^{\mathrm{b}}$ & $27,36^{\mathrm{ab}}$ \\
\hline $0,25 \%$ & $3,54^{\mathrm{ab}}$ & $7,75^{\mathrm{a}}$ & $10,26^{c}$ & $5,39^{b c}$ & $13,07^{\mathrm{b}}$ & $0,48^{\mathrm{b}}$ & $28,03^{\mathrm{a}}$ \\
\hline $0,75 \%$ & $3,53^{\mathrm{ab}}$ & $7,41^{\mathrm{a}}$ & $12,65^{\mathrm{ab}}$ & $6,07^{\mathrm{a}}$ & $13,03^{\mathrm{b}}$ & $0,64^{\mathrm{a}}$ & $22,00^{\mathrm{b}}$ \\
\hline $1,00 \%$ & $3,60^{\mathrm{a}}$ & $7,70^{\mathrm{a}}$ & $13,41^{\mathrm{a}}$ & $5,75^{\mathrm{ab}}$ & $15,63^{\mathrm{a}}$ & $0,58^{\mathrm{ab}}$ & $27,38^{\mathrm{ab}}$ \\
\hline 8 & $3,50^{\mathrm{b}}$ & $7,02^{\mathrm{a}}$ & $12,05^{\mathrm{a}}$ & $5,19^{\mathrm{b}}$ & $13,53^{\mathrm{a}}$ & $0,58^{\mathrm{a}}$ & $25,03^{\mathrm{a}}$ \\
\hline 15 & $3,54^{\mathrm{ab}}$ & $6,54^{\mathrm{a}}$ & $11,40^{\mathrm{a}}$ & $5,87^{\mathrm{a}}$ & $13,99^{\mathrm{a}}$ & $0,55^{\mathrm{a}}$ & $26,22^{\mathrm{a}}$ \\
\hline 22 & $3,57^{\mathrm{a}}$ & $7,02^{\mathrm{a}}$ & $11,67^{a}$ & $5,54^{\mathrm{ab}}$ & $13,57^{\mathrm{a}}$ & $0,54^{\mathrm{a}}$ & $26,84^{\mathrm{a}}$ \\
\hline 29 & $3,58^{\mathrm{a}}$ & $5,99^{\mathrm{a}}$ & $11,90^{\mathrm{a}}$ & $5,69^{\mathrm{ab}}$ & $13,59^{\mathrm{a}}$ & $0,51^{\mathrm{a}}$ & $27,11^{\mathrm{a}}$ \\
\hline CV (\%) & 2,74 & 21,82 & 15,07 & 9,63 & 11,02 & 18,81 & 21,54 \\
\hline
\end{tabular}

Textura (N); U: umidade (\%); AA: ácido ascórbico (mg ác. ascórbico. $\left.100 \mathrm{~g}^{-1}\right)$; SS: sólidos solúveis ( ${ }^{\circ}$ Brix); AT: acidez titulável (g ác. tartárico.100g ${ }^{-1}$ ). Médias seguidas de pelo menos uma letra comum, nas colunas, não diferem significativamente entre si pelo teste de Tukey $(\mathrm{p}<0,05)$.

Tabela 4. Valores médios das características sensoriais de uvas 'Itália' revestidas com películas de alginato de sódio em diferentes concentrações e armazenadas sob refrigeração $\left(4^{\circ} \mathrm{C} ; 49,5 \%\right.$ UR).

\begin{tabular}{cllll}
\hline Tratamento (\%) & $\mathbf{1}$ dia & $\mathbf{8}$ dias & 15 dias & 29 dias \\
\hline 0 & $7,60^{\mathrm{aA}}$ & $7,90^{\mathrm{aA}}$ & $8,23^{\mathrm{aA}}$ & $7,13^{\mathrm{aA}}$ \\
0,25 & $7,03^{\mathrm{aA}}$ & $7,67^{\mathrm{aAB}}$ & $7,50^{\mathrm{aAB}}$ & $7,07^{\mathrm{aA}}$ \\
0,50 & $7,27^{\mathrm{abA}}$ & $6,57^{\mathrm{bBC}}$ & $6,53^{\mathrm{bB}}$ & $7,17^{\mathrm{aA}}$ \\
0,75 & $7,07^{\mathrm{abA}}$ & $6,03^{\mathrm{bC}}$ & $6,90^{\mathrm{abB}}$ & $7,97^{\mathrm{aA}}$ \\
1,00 & $7,57^{\mathrm{aA}}$ & $7,10^{\mathrm{aABC}}$ & $7,63^{\mathrm{aAB}}$ & $7,37^{\mathrm{aA}}$ \\
\hline
\end{tabular}

Impressão global (1: desgostei extremamente a 9: gostei extremamente). Médias seguidas de pelo menos uma letra comum, minúscula nas linhas e maiúscula nas colunas, não diferem significativamente entre si pelo teste de Tukey $(\mathrm{p}<0,05)$. 
detectaram perda da qualidade sensorial, podendo-se afirmar que as uvas foram bem aceitas ao longo de todo o período, pois não foram observados valores médios inferiores a 5 , considerado como limite entre aceitação e rejeição. Os provadores destacaram nas uvas o sabor agradável, a textura firme e a boa aparência das amostras, indo ao encontro dos resultados obtidos nas avaliações físicas e químicas.
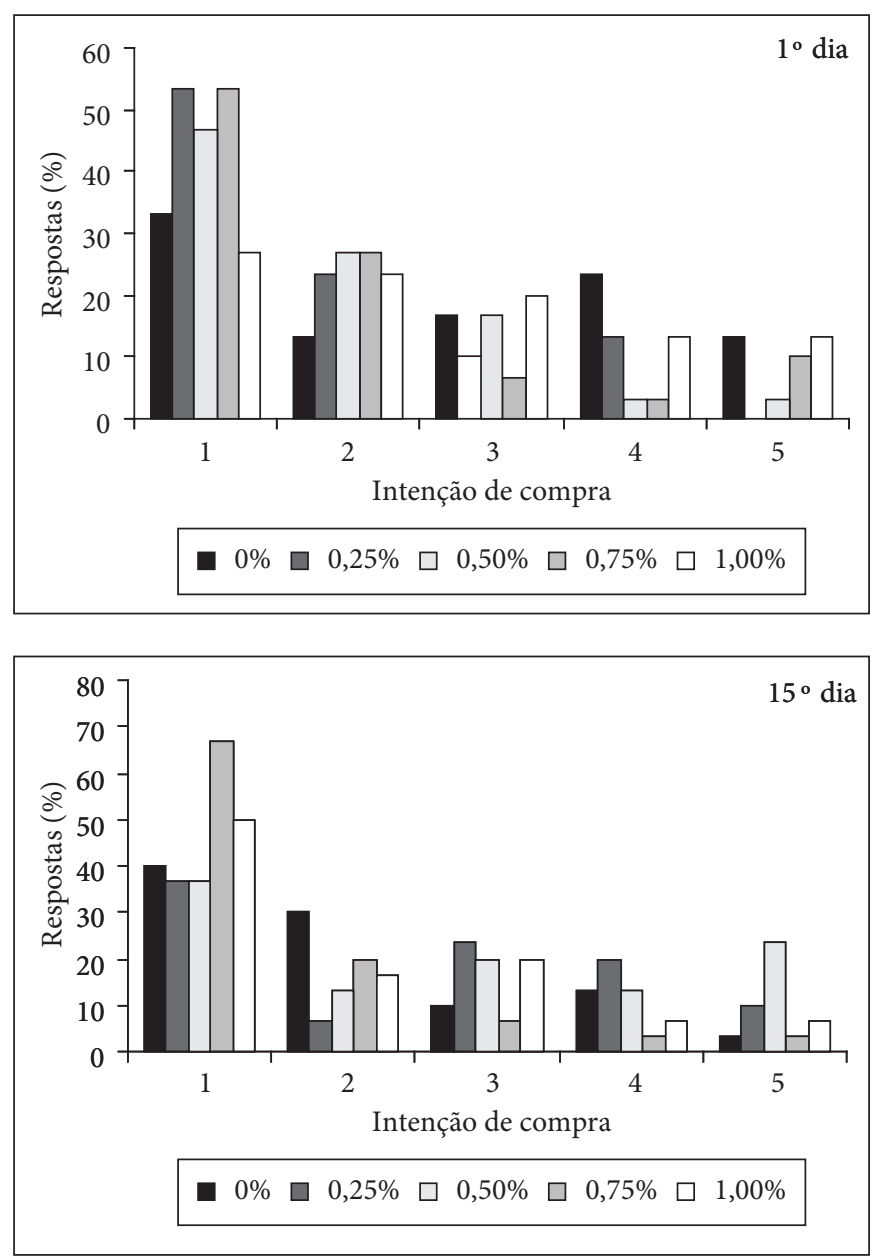

Com relação à intenção de compra, verificou-se que as amostras foram bem aceitas pelos provadores durante os 29 dias de armazenamento, uma vez que a maioria atribuiu notas entre 1 e 2 , correspondentes a 'certamente compraria' e 'provavelmente compraria' (Figura 1). Tais resultados corroboram com os obtidos na avaliação sensorial, cujos provadores atribuíram notas semelhantes aos tratamentos.
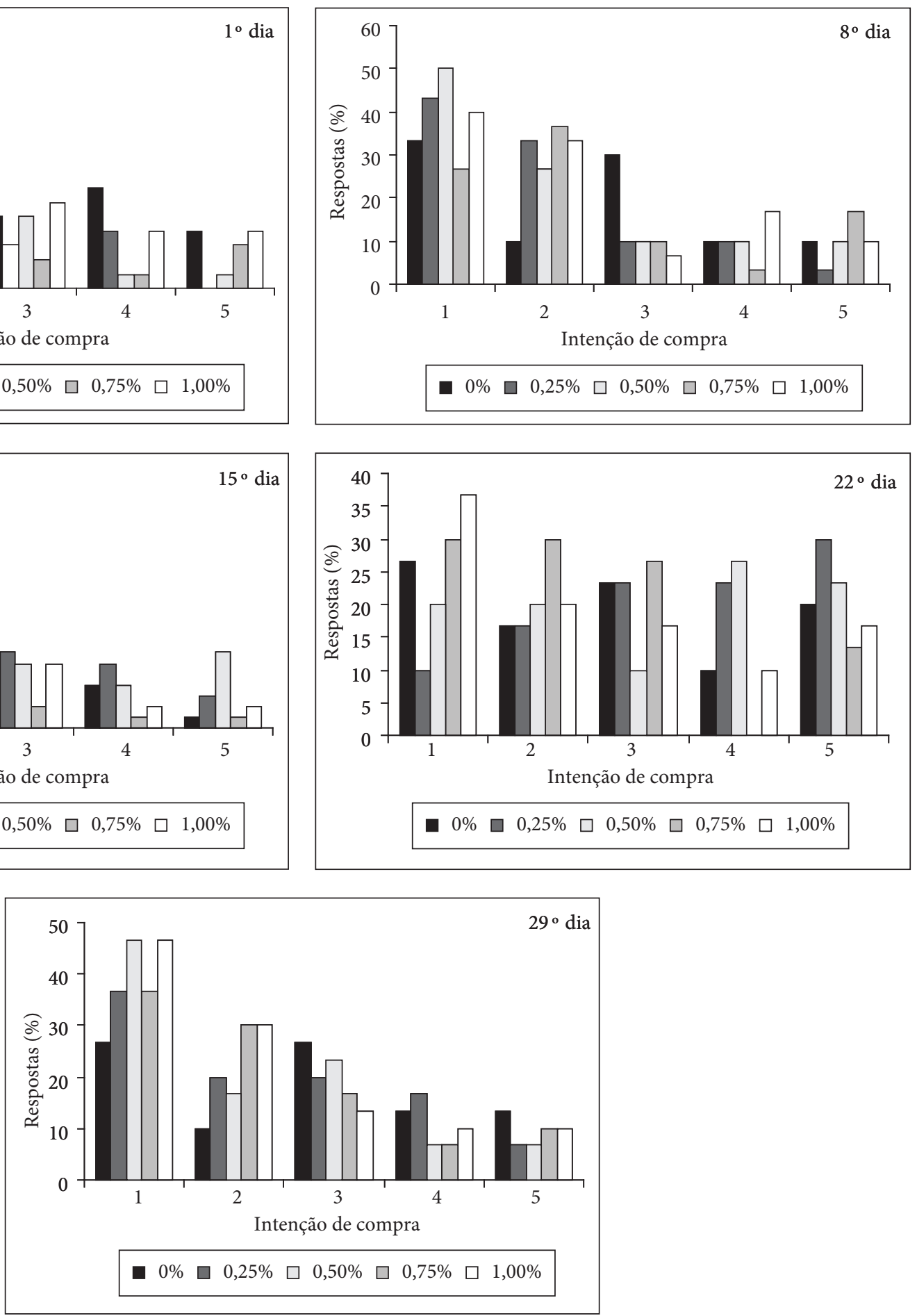

Figura 1. Distribuição percentual das respostas de intenção de compra de uvas 'Itália' revestidas com películas de alginato de sódio em diferentes concentrações e armazenadas sob refrigeração $\left(4{ }^{\circ} \mathrm{C} ; 49,5 \%\right.$ UR). 1 = certamente compraria; 2 = provavelmente compraria; $3=$ talvez compraria/ talvez não compraria; 4 = provavelmente não compraria; e 5 = certamente não compraria. 


\section{Conclusões}

A utilização de película à base de alginato de sódio $1 \%$ mostrou-se mais eficiente na conservação da uva 'Itália' por ter proporcionado uma menor perda de massa e maiores teores de umidade, ácido ascórbico e de sólidos solúveis, em comparação à testemunha e às demais concentrações testadas. A análise sensorial indicou que as uvas foram bem aceitas ao longo de todo o período de armazenamento.

\section{Referências bibliográficas}

ALLEN, L. et al. Edible corn-carbohydrate food coatings, I. Development and physical testing of a starch-algin coating. Food Technology, v. 17, p. 1437-1441, 1963.

Association of Analytical Chemists International - AOAC. Official methods of analysis. $14 \mathrm{ed}$. Washington, 1992.

CARRARO, A. F.; CUNHA, M. M. da. Manual de exportação de frutas. Brasília: Ministério da Agricultura, do Abastecimento e da Reforma Agrária; FRUPEX/Instituto Interamericano de Cooperação para a Agricultura, 1994. 252 p.

CARVALHO, V. D.; CHITARRA, M. I. Aspectos qualitativos da uva. Informe Agropecuário, v. 10, n. 117, p. 75-79, 1984.

CENCI, S. A. Ácido naftalenoacético (ANA) e cloreto de cálcio na pré-colheita de uva niágara rosada (Vitis labrusca $\mathrm{L} . \times$ Vitis vinifera L.): avaliação do potencial de conservação no armazenamento. Lavras, 1994. 109p. Tese (Doutorado em Ciência dos Alimentos) - Universidade Federal de Lavras - UFLA.

CHITARRA, M. I. Alterações bioquímicas do tecido vegetal com o processamento mínimo. In: SEMINÁRIO SOBRE HORTALIÇAS MINIMAMENTE PROCESSADAS, 1999. Palestras... Piracicaba: ESALQ-USP, 1999.

CHITARRA, A. B.; ALVES, R. E. Tecnologia de pós-colheita para frutas tropicais. Fortaleza: FRUTAL - SINFRUTA, 2001.

CHITARRA, M. I. F.; CHITARRA, A. B. Pós colheita de frutas e hortaliças: fisiologia e manuseio. 2 ed. Lavras: UFLA, 2005.

DETONI, A. M. et al. Uva 'Niágra Rosada ' cultivada no sistema orgânico e armazenada em diferentes temperaturas. Ciência e Tecnologia de Alimentos, v. 25, n. 3, p. 546-552, 2005.

FONTES, L. C. B. Uso de solução conservadora e de películas comestíveis em maçãs da cultivar Royal Gala minimamente processadas: efeito na fisiologia e na conservação. Piracicaba, 2005. 118 p. Dissertação (Mestrado em Ciência e Tecnologia de Alimentos) - Escola Superior de Agricultura "Luiz de Queiroz" (ESALQ).

GAYET, J. P. Características das frutas de exportação. In: GORGATTI NETTO, A. et al. Uvas para exportação: procedimentos de colheita e pós-colheita. Brasília: Embrapa-SPI, 1993. 40p. (Série Publicações Técnicas Frupex, 2).

GOMES, F. P. Curso de estatística experimental. 10 ed. São Paulo: Nobel, 1982.

INSTITUTO ADOLFO LUTZ. Normas Analíticas do Instituto Adolfo Lutz; métodos químicos e físicos para análises de alimentos. São Paulo, 1985.

KARABULUT, O. A. et al. Postharvest ethanol and hot water treatments of table grapes to control gray mold. Postharvest Biology and Technology, v. 34, p. 169-177, 2004.

KESTER, R.; FENNEMA, O. R. Edible Films and Coatings: A Review. Food Technology, v. 40, p. 47-59, 1986.

KING, A. H. Brow seawed extracts (Alginates). In: FOOD hydrocolloids. Boca Raton: M.Glicksman, 1983. v. 2.

KLUGE, R. A. et al. Fisiologia e manejo pós-colheita de frutas de clima temperado. 2 ed. Pelotas: UFPEL, 2002.

KROCHTA, J. M.; MULDER-JOHNSTON, C. de. Edible and biodegradable polymer films: challenges and opportunities. Food Technology, v. 51, n. 2, p. 61-74, 1997.

LAVEE, S.; NIR, G. Grape. In: MONSELISE, S. P. CRC Handbook of fruit set and development. Boca Raton: CRC Press, 1986.

LIMA, M. A. C. de. Desenvolvimento, maturação e armazenamento refrigerado de uva 'Itália' sob influência do cálcio. Ceará, 1998. 121p. Dissertação (Mestrado) - Universidade Federal do Ceará - UFC.

MEILGAARD, M.; CIVILLE, G. V.; CARR, B. T. Sensory evaluation techniques. 2 ed. Florida: CRC, 1991.

MINOLTA CORP. Precise color communication: color control from feeling to instrumentation. Ramsey: Minolta Corporation Instrument Systems Division, 1994.

SALUNKE, D. K.; BOLIN, H. R.; REDDY, N. R. Storage processing and nutritional quality of fruits and vegetables: fresh fruits and vegetables. 2 ed. Boca Raton: CRC Press, 1991. 323 p.

SALUNKHE, D. K.; DESAI, B. B. Postharvest biotechnology of fruits. Boca Raton: CRC Press, 1984.

STROHECKER, R.; HENNING, H. M. Analisis de vitaminas: métodos comprobados. Madrid: Paz Montalvo, 1967.

WHISTLER, R. L.; BEMILLER, J. N. Carbohydrate chemistry for food scientists. San Diego: Academia Press, 1997. 214 p.

WHISTLER, R. L.; BEMILLER, J. N.; PASCHALL, E. F. Starch chemistry and technology. San Diego: Academic Press, 1984.

WINKLER, A. J. et al. General Viticulture. 2 ed. Berkeley: University of California Press, 1974. 